Елена Назарбаева

\title{
СОЦИАЛЬНЫЙ ТУРИЗМ В РОССИИ: ПОТЕНЦИАЛЬНЫЕ ТУРИСТЫ И ДОСТУПНЫЕ ВОЗМОЖНОСТИ
}

Туризм стал предметом изучения исследователей как один из объектов потребления. Возможность поехать в отпуск воспринимается как одна из базовых потребностей, а доступ к туристическим услугам- одновременно как индикатор и как источник неравенства. Одним из способов снижения диспропорций в доступе к путешествиям является развитие социального туризма, трактуемого как поездки для незащищенных групп населения при поддержке государства или негосударственных организаций. Потребителями таких услуг, как правило, являются люди с ограниченными возможностями здоровья, пожилые, дети и малообеспеченные семьи с детьми. Степень их вовлеченности в процессы социального туризма варьируется от страны к стране. В статье описывается состояние сферы социального туризма в России и определяются группы населения, нуждающиеся в получении подобной социальной поддержки. Анализ документов и результатов «Выборочного наблюдения доходов населения и участия в социальных программах» дал возможность показать, кто может претендовать на помощь со стороны государства при организации поездок, какие домохозяйства чаще сталкиваются с невозможностью провести отпуск вне дома и какие еще лишения они испытывают. Нормативные акты зачастую не оперируют понятием «социальный туризм», однако предполагают помощь нуждающимся в форме предоставления путевок, организации экскурсий и оплаты стоимости проезда. Большинство мер затрагивают лиц с ограниченными возможностями здоровья, однако на помощь могут претендовать практически все социально незащищенные группы населения. Рискам исключённости из туристической сферы подвержены социально незащищенные люди. А среди тех, кто сталкивается с невозможностью поехать в отпуск, преобладают семьи, в составе которых есть пожилые. Проблемы с организацией отпуска

Елена Алексеевна Назарбаева - аналитик, Центр анализа доходов и уровня жизни, Институт социальной политики, Национальный исследовательский университет «Высшая школа экономики», Москва, Россия. Электронная почта: enazarbaeva@hse.ru 
сопровождаются и другими лишениями, чаще всего это невозможность заменить пришедшую в негодность мебель, купить две пары подходящей по сезону удобной обуви и приглашать гостей. В то же время недоступность туристических поездок не является особенностью бедного населения: даже среди более обеспеченных семей процент испытывающих трудности достаточно велик, что свидетельствует об актуальности изучения и развития сферы социального туризма.

Ключевые слова: социальный туризм, социальная поддержка, потребление туристических услуг, социально незащищенные группы населения

DOI: $10.17323 / 727-0634-2020-18-1-53-68$

\section{Введение}

Отпуск и туристические поездки являются неотъемлемой составляющей жизни большого количества россиян. Согласно данным Ростуризма за период с января по июнь 2018 г., граждане нашей страны совершили около 18 млн поездок в зарубежные страны (Ростуризм 2018). При этом по данным ВЦИОМ, в 2017 г. $47 \%$ россиян планировали провести лето дома, 44 \% из них объясняли это нехваткой денег (ВЦИОМ 2017). Иными словами, туризм популярен в России, однако желание поехать в отпуск зачастую ограничено материальными возможностями.

Преодолеть эту проблему должен помочь социальный туризм - форма социальной поддержки, при которой незащищенные слои населения могут принять участие в поездках, полностью или частично финансируемых государством или негосударственными организациями. Такого рода помощь нуждающимся может оказывать положительное влияние как на ее получателей, так и на развитие туристической сферы в целом, помогая занятым в ней компаниям преодолеть сезонные колебания спроса, предоставив места по сниженным ценам социальным туристам. Подобные схемы за рубежом реализованы на платформе eCalypso, объединяющей участников туристического рынка и потенциальных клиентов (eCalypso 2018). Однако в России социальный туризм не столь популярен. Реализация программ отдана региональным властям, которые не всегда уделяют должное внимание этой составляющей социальной политики. Сложно найти и статистические данные, иллюстрирующие состояние этой сферы.

В статье анализируется сфера социального туризма в России. Первая часть посвящена анализу взглядов на туризм социальных исследователей, вторая содержит характеристику данной сферы в нашей стране. Третья часть затрагивает вопросы о том, какие группы населения лишены возможности поехать в отпуск и кому уже удалось получить поддержку для участия в туристических поездках. В заключении выделим ключевые тезисы и подведем итоги проведенного анализа. 


\section{Туризм как объект потребления и право человека}

Туризм привлек внимание социальных исследователей как объект изучения относительно недавно. В 1990 г. Джон Урри указал на то, что такой отрасли как социология путешествий не существует (Urry 1990:24). Он же утверждал, что туризм можно рассматривать наряду с материальными объектами как один из предметов потребления, а также обратил внимание, что туризм является одной из сфер, где ярко проявляется общественное неравенство: сначала оно выражалось в наличии доступа к путешествиям только у обеспеченных слоев населения, позднее различия стали заключаться в том, куда могут поехать путешественники.

Отсутствие доступа к туристическим поездкам постепенно превратилось из показателя неравенства в индикатор бедности. Так, еще в 1980 г. Джоанна Мак и Стюарт Лансли показали, что возможность проводить одну неделю в год вне дома, не у родственников, по мнению $63 \%$ жителей Англии, является одной из базовых возможностей, которые должны иметь все жители Великобритании (Mack, Lansley 1985: 54). Россияне менее требовательны к наличию отпуска: согласно результатам опросов 2003 и 2013 гг., ограниченные возможности проведения досуга считали признаками бедности $33 \%$ и 32 \% всех опрошенных соответственно (Тихонова 2014).

Возможность путешествовать является не только проявлением неравенства, но и служит инструментом его закрепления. Опираясь на работы Марка Грановеттера (Грановеттер 2009), показавшего силу социальных сетей, и используя теорию капиталов Пьера Бурдье (Бурдье 2005), Урри вводит понятие «сетевой капитал». Он утверждает, что социальные сети приносят пользу их членам только в случае, если они были активированы посредством встреч. И здесь ключевую роль играет туризм, дающий как возможность формировать сети, заводя новые знакомства, так и активировать их, периодически встречаясь с их участниками (Urry 2012).

Уже само видение туризма как индикатора неравенства с одной стороны и его катализатора с другой, дает основания говорить о необходимости поддержки тех, кто лишен возможности путешествовать. Наличие такой возможности обеспечивается в том числе признанием отпуска неотъемлемым правом человека, зафиксированным ООН в 1948 г. Международная организация туризма в 1982 г. включила свободу перемещения в перечень ключевых концепций для развития мирового туризма (Richards 1999). В 1963 г. создана Международная организация социального туризма (International Social Tourism Organization), в ее официальных документах социальный туризм понимался как результат участия населения (особенно низкодоходных групп) в туристических процессах. Размытость границ такого определения была очевидна уже на момент его принятия (Bélanger, Jolin 2011). 


\section{Социальный туризм за рубежом}

Несмотря на то что термин «социальный туризм» активно используется, его понимание варьируется. В Англии и Ирландии акцент сделан на туризме для людей с ограниченными возможностями. В континентальной Европе популярна концепция «туризма для всех». Германия и Англия ориентированы в большей степени на поддержку семей, Польша- на поддержку детей. Бельгия и Франция позиционируют себя как охватывающие широкий круг нуждающихся (Diekmann, McCabe 2011). Франция при этом сочетает различные формы помощи: от молодежных деревень до международных поездок для взрослых (Caire 2011). В Бразилии действуют программы поддержки путешествий для пожилых, работников бюджетной сферы и молодежи (Vilela de Almedia 2011).

Социальный туризм характеризуется, во-первых, способом финансирования: деньги может получать напрямую отправляющийся в поездку турист или же они могут быть переданы организациям для развития инфраструктуры социального туризма; во-вторых, различаются целевые группы, включенные в процессы социального туризма. Перечень их примерно одинаков (инвалиды, дети и молодежь, пожилые граждане, многодетные, малообеспеченные семьи), однако от страны к стране варьируются объем направляемой им поддержки и источники помощи (государство, некоммерческие, общественные или коммерческие организации). В-третьих, различаются формы социального туризма: поездки в досуговые центры, путешествия за рубеж, посещение языковых школ и лагерей (Diekmann, McCabe 2011).

Интервью с представителями зарубежных благотворительных организаций также свидетельствуют о том, что помощь при организации поездок может оказываться в разной форме. Для сбора денег они зачастую проводят благотворительные мероприятия. При предоставлении помощи стараются поддерживать не конкретного человека, а его семью и близких (Hunter-Jones 2011).

С середины 1990-х гг. социальный туризм стал восприниматься не только как способ обеспечить равный доступ к туристическим услугам, но и как инструмент социальной политики, ориентированный на достижение определенных целей (Bélanger, Jolin 2011). Авторам исследований удалось показать, что участие в социальных туристических поездках улучшает семейные отношения, повышает уверенность родителей в себе в отношениях с детьми, способствуют формированию новых связей и поиску друзей (Minnaert et al. 2009). Социальные туристы выше оценивают свою социальную жизнь, количество времени на отдых, способы организации досуга и т.д. Они чувствуют себя более счастливыми и оптимистичными. Но после отпуска снижается их удовлетворенность своим статусом занятости (McCabe, Johnson 2013). 
Если данные о социальном туризме за рубежом существуют, то об оценках социального туризма в России говорить сложнее. Явление вызывает интерес исследователей, трактуется максимально широко- от оплаты поездок больных к месту лечения до поездок для военнослужащих,- и редко подвергается количественным оценкам.

\section{Социальный туризм в России}

\section{Обзор исследований}

Исторически в России в основе массового туризма лежал туризм социальный (Михалев 2012). В СССР он не рассматривался как экономически значимая отрасль, а виделся как отрасль социальной политики. «Социальность» туризма достигалась за счет того, что финансирование поездок осуществлялось из фондов социального страхования и бюджетных источников. Главным организатором поездок выступали профсоюзы- Центральный совет по туризму и экскурсиям ВЦСПС (Путрик 2008). Масштаб работы последнего был достаточно велик. Его годовой оборот составлял до 5 млрд долл. США в нынешнем эквиваленте, ежегодными услугами пользовались 50 млн человек (Трофимов 2014).

В 1970-1980 гг. была развита сеть плановых всесоюзных маршрутов, распространение путевок осуществлялось в основном через профсоюзные комитеты. Путем прямой реализации через бюро путешествий и экскурсий путевки продавались реже, количество таких бюро составляло менее 1000 по всей стране (Путрик 2008). К началу 1990-х гг. мероприятиями социального туризма было охвачено около 300 млн человек (Бадин 2008). После распада СССР понятие социального туризма появилось в Федеральном законе «Об основах туристской деятельности в Российской Федерации», действующем до сих пор (Путрик 2008).

На сегодняшний день реализация социального туризма организована по принципу «островков» туризма, т.е. работа по его развитию ведется эпизодически в отдельных регионах. Существует как корпоративная социальная поддержка, когда путевки или помощь в организации отдыха сотрудникам оказывает предприятие, так и региональные социальные программы поддержки нуждающихся в отдыхе (Трофимов 2014). Уровень развития социального туризма неодинаков для различных целевых групп. Лучше всего развит туризм молодежный, на втором месте- паратуризм, менее популярен туризм для пожилых (Аникеева 2012). Но, по мнению Елены Луганской, за последнее десятилетие социальный туризм в России практически исчез (Луганская 2012).

Российскими авторами была предпринята попытка оценить масштабы социального туризма в России (Vinogradova et al. 2015). Они провели оценку количества потенциальных потребителей услуг социального туризма 
в зависимости от размера соответствующих целевых групп, а также анализ условий и возможностей для возникновения социального туризма. Исследователи сформулировали ряд рекомендаций по развитию социального туризма. В их числе создание новых структур в туристической сфере (например, Департамента социального туризма), вовлечение Министерства природных ресурсов и экологии и Министерства науки и высшего образования в развитие социального туризма и внедрение нормативно-правовых актов, определяющих приоритетные направления развития этой сферы.

Обзор исследований, посвященных социальному туризму, представляется полезным, но не единственным способом описания данной сферы. Возможности получения помощи для организации путешествий различными группами населения во многом определяются действующим законодательством. Остановимся на его анализе более подробно. ${ }^{1}$

\section{Законодательное регулирование сферы социального туризма}

В первую очередь можно отметить, что специальных документов, которые регламентировали бы деятельность в сфере социального туризма, нет. Документы, касающиеся сферы туризма задают, скорее, стратегическое видение туризма социального. Ключевым можно назвать Ф3-132 «Об основах туристской деятельности в Российской Федерации». Социальный туризм в нем определяется как «полностью или частично осуществляемый за счет бюджетных средств, средств государственных внебюджетных фондов (в том числе средств, выделяемых в рамках государственной социальной помощи), а также средств работодателей». Наряду с внутренним, въездным, детским и самостоятельным, туризм социальный указан в числе приоритетных направлений государственного регулирования. А организация и проведение мероприятий, направленных на его поддержку, перечислены в сфере полномочий органов государственной власти.

Постановление правительства «О федеральной целевой программе "Развитие внутреннего и въездного туризма в Российской Федерации (2011-2018 годы)"» содержит упоминание только об одной из его составляющих - оздоровительном туризме. Целевые индикаторы выполнения программы не охватывают показателей, позволяющих выявить изменения в сфере социального туризма. Часть из них дает возможность только косвенно оценить масштаб охвата населения услугами социального туризма.

Социальный туризм упоминается, однако, в подпрограмме 3 «Туризм» государственной программы «Развитие культуры и туризма» на 20132020 гг. Одним из ее приоритетов является

развитие механизмов социального туризма как государственной и корпоративной поддержки туристских поездок к объектам культурного,

\footnotetext{
${ }^{1}$ Анализ документов проведен на основе списка нормативных актов, представленного в сборнике «Социальный туризм...» (Копцева 2015: 21-23).
} 
исторического и природного наследия граждан с ограниченными возможностями, малоимущих и других социально слабозащищенных категорий граждан.

Еще один знаковый документ для развития сферы туризма сегодняСтратегия развития туризма в РФ до 2020 г. В рамках которой реализация и усиление социальной роли туризма видится как одна из ключевых задач. В части развития социального туризма ожидается привлечение бюджетных и внебюджетных средств для его финансирования и повышение доступности туристских услуг. Каждый регион должен уделить внимание этой задаче. Акцент делается на поощрении работодателей, готовых финансировать социальные поездки, поддержке любых инициатив бизнес-сообщества по развитию социального туризма и повышении доступности туристических услуг для незащищенных слоев населения.

Выше речь шла о документах, непосредственно касающихся туризма. Несложно заметить, что они задают только общий вектор развития, однако практически не содержат информации о том, что именно, кем и как должно быть сделано в сфере социального туризма. Трактуя эту область соцполитики максимально широко, стоит обратиться к нормативным актам, регламентирующим деятельность в сферах отличных от туристической. В них постулируются формы поддержки, которые по своей сути могут быть отнесены к социальному туризму.

Федеральный закон от 28.12.2013 № 442-Ф3 «Об основах социального обслуживания граждан в Российской Федерации» включает в перечень социальных услуг формирование позитивных интересов (в том числе в сфере досуга) и организацию досуга (праздники, экскурсии и другие культурные мероприятия). Последнее представляет собой не что иное как одну из форм социального туризма. Закон выделяет основные группы получателей социальных услуг, в их числе люди с ограниченными возможностями здоровья, инвалиды и их семьи, дети и семьи с детьми, граждане без определенного места жительства, не имеющие работы и средств к существованию, семьи в трудной жизненной ситуации. Закон также определяет источники финансирования для оказания социальных услуг. Это бюджетные средства, взносы и пожертвования, средства самих получателей социальных услуг и доходы организаций социального обслуживания.

Социальный туризм затрагивает и ФЗ от 17.07.1999 № 178-Ф3 «О государственной социальной помощи». Он регулирует предоставление путевок на санаторно-курортное лечение и бесплатный проезд на пригородном железнодорожном транспорте и междугородном транспорте к месту лечения и обратно. Претендовать на получение социальной помощи могут инвалиды войны, ветераны и участники ВОВ (закон подробно описывает категории потенциальных получателей услуг из этой категории), ветераны боевых действий, инвалиды и дети-инвалиды. Закон также регламентирует сроки лечения для различных групп населения. 
Отдельно стоит сказать о документах, регулирующих деятельность в сфере здравоохранения. Задавая правила отправки больных на лечение или реабилитацию, они вносят свой вклад в регулирование социального туризма. Федеральный закон от 21.11.2011 № 323-Ф3 «Об основах охраны здоровья граждан в Российской Федерации» отдает в ведение субъектов РФ организацию мероприятий по профилактике заболеваний и формированию здорового образа жизни. Помимо этого, он указывает, что порядок медицинской реабилитации и санаторно-курортного лечения утверждается федеральным органом исполнительной власти.

Выше мы уже упоминали, что инвалиды могут являться получателями путевок на санаторно-курортное лечение. Эти же возможности определяет Федеральный закон от 24.11.1995 № 181-Ф3 «О социальной защите инвалидов в Российской Федерации», включая санаторно-курортное лечение в перечень мер по реабилитации и абилитации инвалидов. Говорили мы уже и о ветеранах, их права на получение путевок в санаторно-курортные организации подтверждает также Федеральный закон от 12.01.1995 № 5-Ф3 «О ветеранах», задавая возможности для различных категорий ветеранов и членов семей погибших участников ВОВ и боевых действий.

В числе наиболее поздних документов- Постановление Правительства РФ от 26.12.2017 N 1640 «Об утверждении государственной программы Российской Федерации "Развитие здравоохранения"». Предложенные меры предполагают развитие диагностики и медицинской помощи в санаторнокурортных учреждениях как для детей, так и для взрослых. Вклад в развитие социального туризма могут внести пропаганда здорового образа жизни и развитие государственно-частного партнерства в сфере охраны здоровья. Также определенное влияние на развитие социального туризма может иметь Национальный проект «Экология», одним из целевых показателей которого является увеличение количества посетителей на особо охраняемых природных территориях.

Обобщая сказанное, можно отметить, что возможности получения помощи согласно федеральному законодательству неодинаковы для различных категорий населения. Так, лица с ограниченными возможностями здоровья могут стать участниками экскурсионных поездок, путевок в санаторно-курортные учреждения и бесплатного проезда на общественном транспорте. Ветераны могут получить путевки и бесплатный проезд на общественном транспорте. А для детей, лиц в трудной жизненной ситуации и малообеспеченных предусмотрена социальная помощи в форме организации экскурсий.

\section{Категории лиц, \\ не имеющих возможности провести отпуск вне дома}

Выше речь шла о том, кто может получить поддержку со стороны государства для организации отпуска. Характеризуя сферу социального 
туризма, не менее важно понять, какие группы населения сталкиваются с проблемами и нуждаются в помощи, и кому действительно удается получить помощь. Сделать это позволяют данные, собранные в рамках Выборочного наблюдения доходов населения и участия в социальных программах (ВНДН). Опрос проводился Федеральной службой государственной статистики и предполагал сбор данных на индивидуальном и домохозяйственном уровне. В 2017 г. в исследовании приняли участие 160008 семей.

Исследование содержит информацию о помощи для оплаты путевок и организации отпуска, полученной семьями из различных источников. Из всех опрошенных подобную поддержку получило около $1 \%$ семей, подавляющее большинство из них - от родственников (80\%). Государственными органами поддержка была оказана $19 \%$ семей, работодателем- $12 \%$. Из-за малого объема групп-получателей социальной поддержки, откажемся от их детального анализа и обратимся к вопросу о том, какие группы населения чаще всего сталкиваются с проблемами в организации отпуска.

Вопрос об этом задается в анкете, касающейся положения семьи в целом, в следующей формулировке: «Принимая во внимание доходы всех членов домохозяйства, есть ли у вашего домохозяйства возможность каждый год одну неделю отпуска проводить вне дома (включая пребывание во втором жилье, у родственников, у друзей)?». Мы будем считать нуждающимися в помощи только тех, кто дал отрицательный ответ. Проблема с организацией отпуска стоит перед многими семьями: 39\% всех домохозяйств указали, что не могут одну неделю отпуска в год провести вне дома. Далее мы рассмотрим, какие именно особенности семьи повышают риски столкнуться с этой проблемой. Понимая, что подобные риски могут быть обусловлены самыми разными факторами, сосредоточимся только на тех, что касаются состава семьи.

\section{Риски столкнуться}

\section{С невозможностью провести отпуск вне дома}

Факторы, положительно связанные с невозможностью уехать в отпуск, во многом повторяют те, что увеличивают риски бедности для населения (подробнее о рисках бедности см.: Овчарова и др. 2014). Семьи с детьми чаще, чем бездетные, не могут позволить себе туристических поездок: $41 \%$ против 38\%. Более тяжелая ситуация отличает многодетные семьи: среди них с такими трудностями сталкиваются 61 \% всех домохозяйств. Наличие членов семьи с ограниченными возможностями также повышает опасность лишиться поездок в отпуск. Среди домохозяйств, в составе которых есть инвалиды, проблемы с отпуском испытывают 57 \% (против $36 \%$ семей без инвалидов). Среди семей, состоящих только из инвалидов, позволить себе отправиться в отпуск могут менее трети (32\%) семей.

Несколько отличается ситуация для семей, в составе которых есть пожилые респонденты. В последние годы исследователи отмечали тенден- 
цию к снижению рисков бедности для пожилых (Овчарова и др. 2014), чего нельзя сказать о рисках провести отпуск дома. Из всех семей, в составе которых есть пожилые респонденты, не могут позволить себе путешествия $46 \%$ домохозяйств.

Отметим также, что семьи, которые не могут позволить себе поездки в отпуск, представлены во всех доходных группах. Процент испытывающих трудности снижается с ростом дохода, но даже в третьем квинтиле треть респондентов не имеют возможность провести отпуск вне дома (в самом бедном квинтиле с такой проблемой сталкиваются- 71 \%, в самом обеспеченном- $10 \%$ ).

Однако невозможность участия в туристических поездках в указанных случаях не обязательно обусловлена недостатком денежных средств: несмотря на отсылку к уровню доходов в вопросе ВНДН, невозможность поехать в отпуск может быть связана и с проблемами со здоровьем, наличием членов семьи, требующих ухода и пр.

\section{Состав группы}

\section{не имеющих возможность проводить отпуск вне дома}

Посмотрим, какие представители населения вошли в состав данной группы. Напомним, что больше всего возможностей для получения помощи в сфере организации поездок имеют лица с ограниченными возможностями здоровья. Однако среди всех семей, не имеющих возможности уехать в отпуск, их процент не очень велик, он составляет $17 \%$ (среди всего населения $12 \%)$.

Более половины семей, испытывающих проблемы с организаций отпуска, имеют в своем составе пожилых. Во многом их высокая доля обусловлена структурой населения, однако можно заметить, что этот показатель выше, чем для выборки в целом (56\% против 47\%).

Около трети семей, не имеющих возможности поехать в отпуск, имеют детей в возрасте до 15 лет, однако этот показатель достаточно близок к показателю для выборки в целом (32\% и $30 \%$ соответственно). Существенный разрыв отличает малоимущие семьи: их доля в выборке в целом составляет 9\%, в то время как среди лишенных возможности поехать в отпуск их больше- $17 \%$ всех опрошенных.

\section{Отсутствие возможности провести отпуск вне дома и другие проблемы домохозяйств}

Выше мы посмотрели, кто чаще всего страдает от отсутствия возможности поехать в отпуск, а также для каких групп населения выше всего риски возникновения сложностей с поездками в отпуск. Посмотрим, какие еще лишения сопутствуют этим проблемам. Чаще всего те, у кого нет возможности поехать в отпуск не могут заменить старую мебель (92\% против $47 \%$ среди тех, у кого нет проблем с организацией отпуска), приобрести 
две пары удобной обуви каждому члену семьи (68\% против $25 \%$ ) и приглашать гостей на семейное торжество (35\% против $4 \%$ ). Последнее подтверждает описанный выше тезис о том, что отсутствие возможности путешествовать зачастую характерна для людей, имеющих меньше социальных связей, чем остальные. Среди рассматриваемых проблем встречаются и связанные с вопросами жизнеобеспечения и выживания, в их числе отсутствие возможности позволить себе питание из мяса, птицы или рыбы через день (21\%) и покупку новой одежды (25\%).

\section{Заключение}

Социальный туризм может быть эффективным инструментом в сокращении неравенства в доступе к путешествиям. Он предполагает оказание помощи нуждающимся (в их числе, как правило, лица с ограниченными возможностями здоровья, дети и молодежь, пожилые и малообеспеченные граждане) в организации отпуска. Доступность такой формы социальной поддержки для различных групп населения варьируется от страны к стране.

В России социальный туризм заявлен как один из приоритетов развития туристической сферы. Однако документов, регламентирующих работу в данном поле, немного. Чаще процессы, которые могут быть описаны в терминах социального туризма, регулируются нормативными актами, не относящимися к тематике туризма. Опираясь на анализ документов, можно сказать, что наиболее широкий перечень мер поддержки путешествий предусмотрен для лиц с ограниченными возможностями здоровья (путевки, оплата проезда и организация экскурсий). Для других категорий социально незащищенных групп населения также есть меры по поддержке туризма, но их меньше.

Опросные данные позволяют оценить, какой процент домохозяйств сталкивается с невозможностью провести отпуск вне дома и, как следствие, нуждается в поддержке. Более трети всех семей, охваченных ВНДН в 2017 г., указывали на наличие этой проблемы. Среди них более половины составили семьи, в составе которых есть пожилые респонденты. Также высока доля семей с детьми. Факторы, увеличивающие вероятность возникновения проблем с поездками, во многом совпадают с теми, что повышают риски бедности. Чаще вынуждены отказываться от отпусков многодетные семьи, домохозяйства в составе которых есть пожилые и инвалиды. При этом проблема доступа к путешествиям не является отличительной особенностью бедных, более обеспеченные семьи также сталкиваются с ней.

Таким образом, можно говорить о потребности в развитии программ социального туризма и необходимости более детальной их проработки и комплексной реализации. 


\section{Выражение признательности}

В статье использованы результаты проекта «Социальная политика, социальная стратификация, компоненты благосостояния населения и проявления неравенства в России: анализ взаимосвязей на различных этапах жизненного цикла», выполненного в рамках Программы фундаментальных исследований НИУ ВШЭ в 2018 г.

\section{Список источников}

Аникеева О.А. (2012) Туризм как технология социальной работы. Научный журнал Сервис Plus, (1): 7-13.

Бадин А.А. (2008) Маркетинговый инструментарий развития социального туризма в Российских условиях. Экономический вестник Ростовского государственного университета, 6 (3/2):222-225.

Бурдье П. (2005) Формы капитала. Экономическая социиология, 6 (3): 60-74.

ВЦИОМ (2017) Лето-2017: отпускные планы и предпочтения россиян. Доступно по ссылке: https://wciom.ru/index.php?id=236\&uid=116235 (дата обращения: 11 октября 2018).

Грановеттер М. (2009) Сила слабых связей. Экономическая соииология, 10 (4): 31-50.

Копцева О.А. (ред.) (2015) Социильный туризм как инструмент повышения качества жизни населения и потенциал социально-экономического развития регионов Российской Федераичи: сборник статей и материалов заочной всероссийской научно-практической конференции. Москва: ПКЦ Альтекс.

Луганская Е.В. (2012) Социальный туризм в трансформирующемся российском обществе. Историческая и сочиально-образовательная мысль, 2 (12): 175-176.

Михалев И.В. (2012) Развитие системы государственного регулирования доступности туризма. Современные проблемы сервиса и туризма, (4): 62-70.

Овчарова Л.Н., Бирюкова С. С., Попова Д. О., Варданян Е. Г. (2014) Уровень и профиль бедности в России от 1990-х годов до наших дней. Москва: НИУ ВШЭ.

Путрик Ю. С. (2008) Развитие сочиального туризма в СССР и Российской Федераичии (70-е г. ХХ в. Начало ХХІ в.). Известия АлтГУ, (4-5): 169-173.

Ростуризм (2018) Въезд-выезд 2018 (утвержденные Росстатом). Доступно по ссылке: https://www.russiatourism.ru/contents/statistika/statisticheskie-dannye-po-rf-2018/ (дата обращения: 11 октября 2018).

Тихонова Н.Е. (2014) Феномен бедности в современной России. Социологические исследования, (1): 7-19.

Трофимов Е.Н. (2014) Социальный туризм в России и в Европе. Вестник PMAT, (3):3-11.

Bélanger Ch., Jolin L. (2011) The International Organization of Social Tourism (ISTO) working towards a right to holidays and tourism for all. Current Issues in Tourism, 14 (5):475-482. 
Caire G. (2011) Social Tourism and the Social Economy. In: S. McCabe, L. Minnaert, A. Diekmann (eds.) Social Tourism in Europe Theory and Practice. Bristol: Channel View Publications: $1-15$.

Diekmann A., McCabe S. (2011) Systems of Social Tourism in the European Union: A Critical Review. Current Issues in Tourism, 14 (5): 417-430.

eCalypso (2018) About eCalypso. Доступно по ссылке: http://www.ecalypso.eu/steep/ public/about.jsf?id=22 (дата обращения: 11 октября 2018).

Hunter-Jones Ph. (2011) The Role of Charities in Social Tourism. Current Issues in Tourism, 14 (5): 445-458.

Mack J., Lansley S. (1985) Poor Britain. London: Allen and Unwin.

McCabe S., Johnson S. (2013) The Happiness Factor in Tourism: Subjective Well-being and Social Tourism. Annals of Tourism Research, (41): 42-65.

Minnaert L., Maitland R., Miller G. (2009) Tourism and Social Policy: The Value of Social Tourism. Annals of Tourism Research, 36 (2):316-334.

Richards G. (1999) Vacations and the Quality of Life: Patterns and Structures. Journal of Business Research, (44): 189-198.

Urry J. (1990) The 'consumption of tourism'. Sociology, 24 (1):23-35.

Urry J. (2012) Social Networks, Mobile Lives and Social Inequalities. Journal of Transport Geography, (21): 24-30.

Vilela de Almedia M. (2011) The Development of Social Tourism in Brazil. Current Issues in Tourism, 14 (5): 483-489.

Vinogradova M., Larionova A., Suslova I., Povorina E., Korsunova M. (2015) Development of Social Tourism: Organizational, Institutional and Financial Aspects. Regional and Sectoral Economic Studies, 15 (2): 123-136. 
Elena Nazarbaeva

\title{
SOCIAL TOURISM IN RUSSIA: POTENTIAL TOURISTS AND AVAILABLE POSSIBILITIES
}

\begin{abstract}
Tourism is increasingly becoming a research object of social science as one of the issues of consumption. The ability to have a vacation is understood as one of the basic needs, while access to tourist services is seen as both an indicator and a source of inequality. Social tourism is one way to reduce disproportions in access to travel. This is usually defined as trips for socially vulnerable groups supported by government or non-governmental organizations. People with disabilities, elderly people, children and their families and poor households are usually the target of such measures. The involvement of different groups in social tourism varies from one country to another. This article is focused on Russian realities. An analysis of regulations and data such as the Survey of Income and Participation of the Population in Social Programs makes it possible to show who can become a part of social tourism, as well as which households most often face difficulties in organizing their vacation and which other deprivations they suffer from. Regulations do not frequently use the term 'social tourism' but still declare support for some groups of people. Most measures are oriented towards the disabled but almost all the socially vulnerable groups do receive some support. Households with elderly people prevail among those who cannot afford going for vacations. The unavailability of tourist trips is not a special trait of poor: even among those who are well-off face difficulties in going on vacation, a point that underlines the importance of studying and development of social tourism.
\end{abstract}

Keywords: tourism, social tourism, social support, tourist services consumption, vulnerable groups

DOI: $10.17323 / 727-0634-2020-18-1-53-68$

\section{References}

Anikeeva O.A. (2012) Turizm kak tekhnologiya social'noy raboty [Tourism as a Technology of Social Work]. Nauchnyy zhurnal Servis Plus [Service Plus], (1): 7-13.

Badin A.A. (2008) Marketingovyy instrumentariy razvitiya social'nogo turizma v Rossiyskih usloviyah [Marketing Tools for Social Tourism Development under Russian Conditions]. Ekonomicheskiy vestnik Rostovskogo gosudarstvennogo universiteta [Economic Bulletin of Rostov State Uniersity], 6 (3/2): 222-225.

Bélanger Ch., Jolin L. (2011) The International Organization of Social Tourism (ISTO) working towards a Right to Holidays and Tourism for All. Current Issues in Tourism, 14 (5):475-482.

Elena Nazarbaeva - analyst, Centre for Studies of Income and Living Standards, Institute for Social Policy, National Research University Higher School of Economics; Moscow, Russian Federation. Email: enazarbaeva@hse.ru 
Bourdieu P. (2005) Formy kapitala [The Forms of Capital]. Ekonomicheskaya sociologiya [Economic Sociology], 6 (3): 60-74.

Caire G. (2011) Social Tourism and the Social Economy. In: S. McCabe, L. Minnaert, A. Diekmann (eds.) Social Tourism in Europe Theory and Practice. Bristol: Channel View Publications: $1-15$.

Diekmann A., McCabe S. (2011) Systems of Social Tourism in the European Union: A Critical Review. Current Issues in Tourism, 14 (5): 417-430.

eCalypso (2018) About eCalypso. Available at: http://www.ecalypso.eu/steep/public/about. jsf?id=22 (accessed 11 October 2018).

Granovetter M. (2009) Sila slabyh svyazey [The Strength of Weak Ties]. Ekonomicheskaya sociologiya [Economic Sociology], 10 (4): 31-50.

Hunter-Jones Ph. (2011) The Role of Charities in Social Tourism. Current Issues in Tourism, 14 (5): 445-458.

Kopceva O. A. (ed.) (2015) Social'nyy turizm kak instrument povysheniya kachestva zhizni naseleniya i potencial social'no-ekonomicheskogo razvitiya regionov Rossiyskoy Federacii: sbornik statey i materialov zaochnoy vserossiyskoy nauchno-prakticheskoy konferencii [Social Tourism as an Instrument of Life Quality Improvement and Potential for Economic Development of Russian Regions]. Moscow: PKC Al'teks.

Luganskaya E. V. (2012) Social'nyy turizm v transformiruyushchemsya rossiyskom obshchestve [Social Tourism in a Transforming Russian Society]. Istoricheskaya i social'noobrazovatel 'naya mysl' [Historical and Social-Educational Idea], 2 (12): 175-176.

Mack J., Lansley S. (1985) Poor Britain. London: Allen and Unwin.

McCabe S., Johnson S. (2013) The Happiness Factor in Tourism: Subjective Well-being and Social Tourism. Annals of Tourism Research, (41): 42-65.

Mihalev I.V. (2012) Razvitie sistemy gosudarstvennogo regulirovaniya dostupnosti turizma [Development of State Regulation System Related to Tourism Accessibility]. Sovremennye problemy servisa i turizma [Service and Tourism: Current Challenges], (4): 62-70.

Minnaert L., Maitland R., Miller G. (2009) Tourism and Social Policy: The Value of Social Tourism. Annals of Tourism Research, 36 (2):316-334.

Ovcharova L. N., Biryukova S. S., Popova D. O., Vardanyan E. G. (2014) Uroven' i profil' bednosti v Rossii ot 1990-h godov do nashih dney [Poverty Level and Profile in Russia From $1990^{\text {th }}$ till Nowadays]. Moscow: NIU VSHE.

Putrik YU.S. (2008) Razvitie social'nogo turizma v SSSR i Rossiyskoy Federacii (70-e g. XXv. nachalo XXI v.) [Development of Social Tourism in USSR and in Russia]. Izvestiya Alt $G U$ [Izvestiya of Altai State University Journal], (4-5): 169-173.

Richards G. (1999) Vacations and the Quality of Life: Patterns and Structures. Journal of Business Research, (44): 189-198.

Rosturizm (2018) V'ezd-vyezd 2018 (utverzhdennye Rosstatom) [Arrivals and Departures 2018]. Available at: https://www.russiatourism.ru/contents/statistika/statisticheskie-dannyepo-rf-2018/ (accessed 11 October 2018). 
Tihonova N. E. (2014) Fenomen bednosti v sovremennoy Rossii [The phenomenon of Poverty in Modern Russia]. Sociologicheskie issledovaniya [Sociological Studies], (1): 7-19.

Trofimov E. N. (2014) Social'nyy turizm v Rossii i v Evrope [Social Tourism in Russia and Europe]. Vestnik RMAT [Vestnik RIAT], (3):3-11.

Urry J. (1990) The 'Consumption of Tourism'. Sociology, 24 (1): 23-35.

Urry J. (2012) Social Networks, Mobile Lives and Social Inequalities. Journal of Transport Geography, (21):24-30.

VCIOM (2017) Leto-2017: otpusknye plany i predpochteniya rossiyan [Summer-2017: Russians PreferencesforVacations].Availableat:https://wciom.ru/index.php?id=236\&uid=116235 (accessed 11 October 2018).

Vilela de Almedia M. (2011) The Development of Social Tourism in Brazil. Current Issues in Tourism, 14 (5): 483-489.

Vinogradova M., Larionova A., Suslova I., Povorina E., Korsunova M. (2015) Development of Social Tourism: Organizational, Institutional and Financial Aspects. Regional and Sectoral Economic Studies, (15/2): 123-136. 